\title{
Medical management of decompensated heart failure in adult patients: Part 2: Organ involvement, invasive hemodynamic monitoring, device therapy, and outcomes
}

\author{
Barbara Mantilla MD, Pablo Paz MD, Rubayat Rahman MD, Mohamed Elmassry MD, \\ Scott Shurmur MD, Erwin Argueta Sosa MD
}

\begin{abstract}
Acute decompensated heart failure is a clinical syndrome involving the congestion of vital organs, such as the kidneys, liver, and brain, leading to loss of autoregulation and multiorgan failure. The interaction between organ systems is bi-directional and complex; it cannot be explained by hypoperfusion alone. Despite the multiple signs and symptoms that arise with systemic congestion, there are limitations in the assessment of volume status based only on clinical evaluation. Invasive hemodynamic monitoring is an adjunctive diagnostic and prognostic tool in acute decompensated heart failure when standard therapy fails and/or leads to worsening renal function as well as for the evaluation of advanced therapy options. This review will discuss the use of temporary mechanical circulatory support devices in cardiogenic shock and the expected outcomes for advanced heart failure with the implementation of left ventricular assist devices and cardiac transplantation.
\end{abstract}

Keywords: acute decompensated heart failure, organ dysfunction, medical management, device therapy

\section{IDENTIFYING END ORGAN INVOLVEMENT IN THE SYSTOLIC HEART FAILURE PATIENT}

\section{RENAL IMPAIRMENT}

It is known that there is an interaction between renal function and the cardiovascular system. From a heart failure perspective in clinical practice, this is appreciated by initial renal function parameters measured in the serum of a patient and changes in these as medical therapy for heart failure is initiated. Thus, when a patient presents with decompensated heart failure and abnormal renal function, it is important to

Corresponding author: Barbara Mantilla Contact Information: Barbara.Mantilla@ttuhsc.edu DOI: $10.12746 /$ swrecc.v8i36.759 distinguish between underlying kidney disease and impaired kidney function precipitated by a collapsing cardiovascular system. Ancillary testing that finds proteinuria, active urine sediment, hematuria, pyuria, or abnormal sized kidneys on radiologic studies usually suggests underlying kidney disease.

Due to the concomitant presence of these diseases the term cardiorenal syndrome (CRS) was initially used broadly for several decades until 2004 when a group of investigators at the National Heart, Lung, and Blood Institute defined the syndrome as a state in which therapy to relieve heart failure (HF) symptoms is limited by further worsening renal function. ${ }^{78}$ Although this seems to be the most common use of the term, some authors argue that it is inaccurate. In 2008, a new definition and classification were proposed by Ronco and colleagues; CRS was defined as a pathophysiologic disorder of the heart and kidneys in which acute 
or chronic dysfunction of one organ may induce acute or chronic dysfunction of the other. ${ }^{79}$ The reduction in GFR was initially thought to result from a reduction in renal blood flow. However, the relationship between heart and kidney is bidirectional; the mechanisms causing CRS seem to be more complex than just reduction of blood flow and include activation of the sympathetic and renin-angiotensin-aldosterone systems, alterations in nitric oxide bioavailability, inflammation, and overproduction of reactive oxygen species. ${ }^{79}$ In these patients a urinary sodium (UNa) below $25 \mathrm{meq} / \mathrm{L}$ can occur and is related to activation of the renin-angiotensin-aldosterone and sympathetic nervous systems causing reduced renal perfusion and sodium retention. Heart failure is also a cause of prerenal azotemia, but evidence suggests that worsening renal function due to HF is not solely related to reduced cardiac output. It frequently occurs in patients with elevated right atrial pressures. ${ }^{80}$ Based on the complex heart-kidney interactions and to emphasize the bidirectional nature of dysfunction in these organs, a new classification was created:

1. Type 1 (acute): an abrupt worsening of cardiac function leading to acute kidney injury (e.g., acute cardiogenic shock or decompensated HF).

2. Type 2: chronic abnormalities in cardiac function (e.g., chronic HF) causing progressive chronic kidney disease (CKD).

3. Type 3: an abrupt worsening of renal function (e.g., AKI or glomerulonephritis) causing acute cardiac dysfunction (e.g., HF, arrhythmia, ischemia).

4. Type 4: CKD (e.g., chronic glomerular disease) contributing to decreased cardiac function, cardiac hypertrophy, and/or increased risk of adverse cardiovascular events.

5. Type 5 (secondary): a systemic condition (e.g., sepsis) causing both cardiac and renal dysfunction. ${ }^{79}$

\section{Congestive HEPATOPATHY}

Liver dysfunction also occurs in HF, and almost every condition that causes right-sided HF can result in hepatic passive congestion, secondary to elevated right ventricular pressures leading to increased central venous pressure (CVP) and liver reduced blood outflow. ${ }^{81}$ Hepatic congestion can be asymptomatic and detected only by abnormal liver tests found at routine laboratory analysis. In the onset of HF there are two forms of liver dysfunction: chronic congestion or volume retention, which is related to increased CVP and associated with total bilirubin elevation, and acute hepatocellular necrosis, which is caused by impaired perfusion and associated with elevation in serum aminotransferases as seen in patients with shock liver. ${ }^{82,83}$ Thus cardio-hepatic syndrome (congestive hepatopathy) shows a predominant cholestatic enzyme pattern (bilirubin, alkaline phosphatase, and $\gamma$-glutamyltranspeptidase); in acute HF, elevated aminotransaminases are characteristic. ${ }^{84}$

When evaluating hemodynamics, an upper safety limit of inferior vena cava (IVC) pressure is about $27 \mathrm{~cm} \mathrm{H}_{2} \mathrm{O}(20.5 \mathrm{~mm} \mathrm{Hg})$, which is already significantly elevated, and a pressure of $35 \mathrm{~cm} \mathrm{H}_{2} \mathrm{O}(26.6 \mathrm{~mm} \mathrm{Hg})$ in the IVC is probably a critical level for maintaining liver viability. ${ }^{85}$

The increase in CVP eventually leads to atrophy of hepatocytes and perisinusoidal edema, impairing oxygen and nutrient diffusion. ${ }^{86}$ Cholestatic enzymes, but not aminotransaminases, are associated with severity and chronicity of HF, and with tricuspid regurgitation severity. ${ }^{84,8}$ It has been demonstrated that right ventricular end-diastolic diameter, right atrial area, tricuspid regurgitation, TAPSE, portal vein pulsatility index, and left ventricular ejection fraction are significant predictors of total bilirubin elevation. ${ }^{88}$

Allen et al. reported that a total bilirubin level above the upper limit level was a prognostic predictor of cardiovascular death, worsening heart failure, and all cause mortality. They concluded that total bilirubin in combination with other characteristics (blood count, basic metabolic panel, age, recent hospitalization, and New York Heart Association functional class) may provide an important estimation of overall risk of morbidity and mortality in patients with $\mathrm{HF}^{89}$

Ultimately the clinical presentation of congestive hepatopathy consists in signs and symptoms of rightsided HF rather than those of liver disease. Hepatomegaly is present in $95-99 \%$ of cases. A mild, dull, 
right upper quadrant pain is caused by Glisson's capsule stretching. A pulsatile liver is the result of volume overload in the right atrium, and loss of such pulsatility implies a progression toward fibrosis or cirrhosis and deserves careful examination. ${ }^{90}$ Ascites may be present in up to $25 \%$ of the patients and is the result of right-sided HF and not from intrinsic liver dysfunction. ${ }^{83}$ As a result, liver abnormalities in an HF patient warrant additional testing to evaluate the morphology and liver synthetic function to distinguish between the presence of primary liver disease and/or its involvement due to abnormal hemodynamics.

\section{HEART FAILURE-INDUCED BRAIN INJURY}

Recent data have demonstrated that cerebral blood flow (CBF) is compromised in HF, suggesting an association with CNS-related symptoms. ${ }^{91}$ Brain hypoperfusion is not only the result of low cardiac output, but cerebral autoregulation is also compromised. ${ }^{92}$ Levels of carbon dioxide levels fluctuate in patients with acute and with chronic HF, being inversely related to left ventricular end-diastolic pressures, causing constriction and dilatation of CNS blood vessels. ${ }^{93,94}$ Georgiadis et al. demonstrated that even though patients with HF had baseline flow-velocities comparable to those of normal controls, their response to the hypercapnic state (which normally causes vasodilation and increased flow) was blunted. ${ }^{92}$

Brain function abnormalities associated with $\mathrm{HF}$ include reduced psychomotor speed, learning and attention deficits, memory dysfunction, reduced executive function, and occasional language alterations. ${ }^{95,96}$ Mechanisms proposed for these changes include a lack of collaterals and watershed phenomena in deep brain structures causing ischemic damage in hypoperfused conditions. ${ }^{97}$

Another aspect that supports the brain injury secondary to heart failure is how cognitive function improves after LVAD implantation and cardiac transplantation. ${ }^{98,99}$ Angiotensin-converting enzyme inhibitors seem to improve cognitive performance not only due to improved cardiac function but because angiotensin-converting enzyme is present in major cerebral arteries, causing an increase in cerebral perfusion. ${ }^{100,101}$

\section{ROLE FOR INVASIVE HEMODYNAMICS MEASUREMENTS}

Invasive hemodynamic monitoring with a pulmonary artery catheter has a specific role in the management of heart failure. Its routine use is not recommended in normotensive patients with acute decompensated heart failure who respond to diuretics and vasodilators. According to the 2013 ACC/AHA guidelines, right heart catheterization is indicated to guide therapy in patients with respiratory distress or clinical evidence of hypoperfusion when there is an unclear understanding of the hemodynamic state based on clinical evaluation (Class I, LOE C). ${ }^{18}$ It is also recommended in symptomatic patients who are refractory to standard treatment and who meet the following clinical scenarios: volume status is uncertain by clinical evaluation, persistent and clinically significant hypotension (symptomatic low blood pressure or SBP $<90 \mathrm{~mm} \mathrm{Hg}$ ), use of parenteral vasoactive agents, and/or worsening renal function despite treatment. (Class Ila, LOE C). These recommendations are also in accordance with the 2016 ESC guidelines. ${ }^{10}$ In addition, invasive hemodynamic monitoring is required for the evaluation of advanced therapy options including mechanical circulatory support (MCS) or cardiac transplantation (Class Ila, LOE C) and is the gold standard for the diagnosis and surveillance of pulmonary artery hypertension. ${ }^{18,102}$

Right heart catheterization is an important tool in determining the etiology of shock and has a prognostic utility in patients with heart failure. ${ }^{102}$ Hemodynamic parameters are used to tailor therapy in patients who require inotropic support. Despite its role in direct heart failure therapy in the intensive care unit, the Swan-Ganz catheter has not been associated with increased survival and has limitations, including an inability to use it in the outpatient setting and provide frequent measurements, operator dependent errors inherent to the procedure, and pressure variation with respiration. ${ }^{102}$

The Evaluation Study of Congestive Heart Failure and Pulmonary Artery Catheterization Effectiveness (ESCAPE) trial in 2015 was a randomized controlled trial of 433 patients designed to determine if pulmonary artery catheterization (PAC) is safe and 
improves clinical outcomes in patients hospitalized with severe symptomatic and recurrent heart failure. ${ }^{103}$ The use of PAC did not affect the primary end point (days alive and out of the hospital during the first 6 months), mortality, or the number of hospitalization days. However, in-hospital adverse events were more common in the PAC group $(p=0.04)$. No information was provided on the use of PAC in cardiogenic shock as this patient population was excluded from the trial. The study results support the recommendation that there is no indication for routine PAC use to adjust therapy for decompensated heart failure. ${ }^{103}$ It is an opinion of the authors that it should be considered on a case by case scenario. Similar results were found in a meta-analysis of 13 RCTs $(n=5051)$ that showed no changes in mortality or days of hospitalization with the use of a PAC device in critically ill patients. ${ }^{104}$

Strategies to prevent heart failure hospitalizations based on clinical assessment alone have not been successful. It has been established that hemodynamic congestion occurs weeks before clinical congestion is evident. ${ }^{105}$ For this reason, the role of remote intracardiac and pulmonary artery pressure monitoring has been explored in an effort to decrease hospitalizations for heart failure. ${ }^{105}$ According to the ESC Practice Guidelines, remote hemodynamic monitoring is recommended in patients with symptomatic heart failure and a recent heart failure hospitalization (class Ilb recommendation). ${ }^{10}$ The HemodynamicGUIDEd Management of Heart Failure (GUIDE-HF) trial is a prospective study at 140 sites who will enroll NYHA class II-IV patients with HF with an elevated BNP and/or prior HF hospitalization (HFH) to demonstrate the effect of a pulmonary artery pressure sensor (CardioMEMS ${ }^{\mathrm{TM}}$ HF System) in HFH, intravenous diuretic visits and all-cause mortality. ${ }^{105}$ Ongoing clinical trials are required to determine which groups of heart failure patients will benefit from remote hemodynamic monitoring.

\section{TEMPORARY MECHANICAL CIRCULATORY SUPPORT IN SYSTOLIC HEART FAILURE}

There are approximately 6 million adults in the United States with congestive heart failure. ${ }^{106}$ The need for percutaneous ventricular assist devices (VAD) in acute decompensated heart failure has emerged with increased survival from myocardial infarction (MI) and heart failure. Timing of circulatory support is critical for improvements in survival. ${ }^{107}$ There is now a role for mechanical circulatory support initiated at earlier heart failure stages, prophylactically in high risk clinical scenarios before shock progresses to end-organ dysfunction and even in some cases of cardiac arrest where spontaneous circulation cannot be achieved by other means. ${ }^{107}$

Ventricular assist devices unload the ventricle, and thereby decrease myocardial oxygen consumption, and promote favorable remodeling, and maintain an adequate systemic pressure and cardiac output (CO) for organ perfusion. ${ }^{107}$ The following section discusses the use of the different forms of mechanical support, including intra-aortic balloon pump (IABP) and continuous aortic flow augmentation (i.e., Impella). In addition, there is a section on extracorporeal membrane oxygenation (ECMO).

\section{INTRA-AORTIC BALLOON PUMP}

The IABP is the most commonly used hemodynamic support device in the treatment of acute heart failure from MI. ${ }^{106}$ The IABP is inserted percutaneously via the femoral artery with the balloon placed in the proximal descending aorta. Inflation of the balloon is synchronized with diastole producing diastolic aortic pressure augmentation that increases coronary artery pressure as well as mean arterial pressure and thus improves coronary, cerebral, and peripheral perfusion. ${ }^{106,107}$ Deflation then occurs before systole to lower aortic end-diastolic and systolic pressures with a resulting reduction in ventricular afterload and myocardial oxygen consumption and improvement in cardiac output (CO). ${ }^{106,107}$

The Intra-Aortic Balloon Counterpulsation in Acute Myocardial Infarction Complicated by Cardiogenic Shock (IABP-SHOCK II) trial showed no mortality reduction of IABP compared with medical therapy in the setting of AMI complicated by cardiogenic shock (30-day mortality $39.7 \%$ with IABP vs. $41.3 \%$ with medical therapy, RR with IABP 0.96, 95\% Cl 0.79-1.17, 
$p=0.69) .{ }^{108}$ Moreover, Stretch et al. demonstrated that IABP prior to the use of contemporary mechanical circulatory support was a predictor of mortality and increased costs ${ }^{106,109}$ The intra-aortic balloon pump is considered a class Ila indication for use during STEMI complicated by cardiogenic shock according to the 2013 ACC/AHA guidelines. ${ }^{106}$

\section{IMPELLA}

The Impella is a percutaneous VAD placed across the aortic valve that provides non-pulsatile blood flow by unloading the left ventricle (LV) and delivering blood to the ascending aorta through a trans-axial pump. ${ }^{106}$ The device works in series with the LV to improve cardiac output. Impella flow is continuous, independent of cardiac rhythm, and offers a different mechanism of circulatory support than the IABP.

Based on the study A Prospective Feasibility Trial Investigating the Use of IMPELLA RECOVER LP 2.5 System in Patients Undergoing High Risk PCI (PROTECT I) trial and A Prospective, Randomized Clinical Trial of Hemodynamic Support With Impella 2.5 Versus IntraAortic Balloon Pump in Patients Undergoing High-Risk Percutaneous Coronary Intervention (PROTECT II) trial, Impella 2.5 and Impella Cardiac Power are approved for use in hemodynamically stable patients undergoing elective or urgent high risk $\mathrm{PCl}(\mathrm{HR}-\mathrm{PCl}){ }^{106,110}$ The PROTECT II study included 452 symptomatic patients with complex multivessel disease or unprotected left main disease and severely depressed LV function. The primary endpoint was a 30-day composite of 11 major adverse events. Results from PROTECT II trial showed that the 30-day incidence of major adverse events was not statistically different for patients with IABP or Impella 2.5 (35.1\% with Impella vs. $40.1 \%$ with IABP, $p=0.227$ ). However, a trend for decreased major adverse events was observed in patients with Impella 2.5 vs. IABP $(40.6 \%$ versus $49.3 \%, P=0.066)$ in the intention-to-treat population at 90 days. ${ }^{106,110}$ Additionally, the catheterbased ventricular assist device (cVAD) registry is an observational, multicenter, retrospective registry of patients supported with Impella that suggests greater survival with pre-PCI Impella insertion compared with pre-PCI IABP and/or pharmacotherapy alone.106,111 The use of Impella in $\mathrm{PCl}$ with cardiogenic shock and in cardiogenic shock with multiorgan failure is a class I indication according to the 2013 ACCF guidelines. ${ }^{106}$

According to the U.S. Impella Registry, early circulatory support (pre-PCl) improved hospital survival to discharge in acute $\mathrm{MI}$ complicated by cardiogenic shock $(65.1 \%$ vs. $40.7 \%$; $p=0.003)$. Using hemodynamic support at early stage permits more complex revascularization $(p=0.003){ }^{107,112}$ Finally, The Use of Impella RP Support System in Patients With Right Heart Failure (RECOVER RIGHT) study performed to determine Impella RP safety and efficacy, showed a $73 \%$ successful survival to either 30 days or to hospital discharge. The FDA has approved the Impella RP for patients with acute right heart failure or decompensation after LVAD implantation, MI, heart transplant, or open-heart surgery. ${ }^{106}$

\section{Veno Arterial Extracorporeal Membrane OXYgenation}

Venoarterial Extracorporeal Membrane Oxygenation (VA-ECMO) is a mechanical cardiopulmonary support used for acute cardiac failure or combined (cardiac and respiratory) failure; veno-venous ECMO is used when respiratory support is needed exclusively. ${ }^{107}$ The VA-ECMO works by removing blood from venous system (RA or IVC) and returning it to the arterial side after gas exchange.

The Extracorporeal Life Support Organization (ELSO) registry reported $27 \%$ survival to hospital discharge with ECMO to support CPR in adults after cardiac arrest; the need for renal replacement therapy increased mortality. ${ }^{113}$ More recent studies have shown $49 \%$ survival with either mechanical support devices or ECMO in cardiogenic shock. Prolonged CPR was a risk factor for increased mortality. ${ }^{113}$ There are no large randomized controlled trials on the use of ECMO. Guidelines recommend ECMO when concomitant hypoxemia and RV failure are present. ${ }^{106,107}$

\section{DeVICE CHOICE}

Percutaneous VADs are used as a bridge to recovery in patients with cardiogenic shock from potentially reversible causes and provide support in high risk 
procedures that attempt to avoid cardiogenic shock precipitants ${ }^{106}$ They can also be used as a bridge to allow time for risks and benefit assessment for more definite treatments like LVAD or heart transplant, also considered bridge to candidacy. ${ }^{106}$

The decision on the device selection should be individualized considering the severity of cardiogenic shock from initial presentation, the degree of mechanical support needed in the setting of left, right or biventricular failure, and the presence of impaired pulmonary function. Several parameters, including circulatory support, ventricular support, and coronary perfusion, help patient selection. ${ }^{107}$

The IABP increases coronary perfusion by diastolic augmentation and provides afterload reduction. It offers less systemic support than other devices and depends on the electrical and mechanical function of the heart. ${ }^{107}$ The Impella does not affect afterload but decreases preload and increases $\mathrm{CO}$ and systemic pressures. According to Sodhi et al., the Impella is more effective than IABP in reducing LV-end diastolic pressure and equally effective in coronary perfusion in the setting of acute decompensated heart failure and shock. ${ }^{106}$ Last, ECMO is the most effective in increasing $\mathrm{CO}$ as well as maintaining oxygenation and systemic blood pressure. It is superior to IABP and Impella because it has the ability to provide independent left, right, and biventricular support at high blood flow rates and respiratory support if required. ${ }^{114}$ However, its effect is limited due to increased myocardial oxygen demand as ECMO has two opposing hemodynamic effects. ${ }^{106}$ When blood is removed from the venous system, preload decreases and there is a reduction in LV end-diastolic volume and pressure with subsequent reduction in wall stress and work. However, as blood returns to the arterial system, there is an increase in LV afterload which in turn causes higher myocardial oxygen consumption and affects cardiac remodeling and recovery. ${ }^{106,115}$ For this reason, ECMO has been used concomitantly with other mechanical support devices for both preload reduction with Impella and afterload reduction with the IABP. ${ }^{107}$ Moazzami et al. showed that the Impella 2.5 serves to unload the LV reducing right atrial pressure, pulmonary capillary wedge pressure, and LV end-diastolic pressure when used with ECMO. ${ }^{115,116}$
While there are favorable hemodynamic effects associated with mechanical support, there is a lack of evidence that demonstrates a survival benefit of the Impella vs. medical therapy and IABP. Guidelines require randomized controlled trials that evaluate the benefit of hemodynamic support in cardiogenic shock.

\section{EXPECTED OUTCOMES AND DISPOSITION}

\section{IS ORGAN RECOVERY A POSSIBILITY?}

The clinical course of heart failure is progressive but nonlinear, characterized by worsening quality of life despite increasing levels of care. ${ }^{117}$ Prognosis in advanced HF is grave, with a 1-year mortality in ambulatory class III-IV patients $>25 \%$ and exceeding $50 \%$ in class IV patients. ${ }^{118}$ However, a subset of patients with HFrEF shows improvement in EF with or without medical therapy. This cohort of cases, regarded as having heart failure with improved ejection fraction (HFiEF), has been shown to have 5-year survival rates of $80 \%$ to $90 \%$, compared with $65 \%$ to $75 \%$ in HFrEF patients. ${ }^{119}$

Patients with HFiEF share demographic and clinical characteristics that are distinct from other classifications of heart failure. Among patients with recent onset ( $<6$ months) HFrEF, Givertz et al. documented rates of LVEF improvement (to LVEF $>50 \%$ ) of $60-100 \%$ among patients with cardiomyopathy due to tachycardia, takotsubo syndrome, and hyperthyroidism. ${ }^{120}$ Punnoose et al. compared patients with HFiEF and HFrEF and found that patients in the former category were younger and less likely to have coronary disease compared with the latter, but rates of atrial fibrillation, hypertension, and diabetes were similar. ${ }^{3}$ Genetic factors may also have a role in organ recovery. Activating mutations in the angiotensin-converting enzyme (ACE) or $\beta 1$-adrenergic receptor genes have been associated with refractoriness to medical therapy, whereas truncating mutations in the titin-A gene have a higher frequency of LVEF improvement $(>10 \%){ }^{121,122}$ Other factors that have been shown to be associated with HFiEF include female sex, shorter duration of HF, and less severe adverse cardiac remodeling at initial evaluation. ${ }^{123}$ However, it 
is important to note that despite having improved or even normalized LVEF, these patients may continue to have clinical and biochemical evidence of functional impairment. ${ }^{124}$

\section{ADVANCED THERAPY OPTIONS}

Developments in advanced heart failure therapeutics in the form of cardiac transplantation and left ventricular assist devices (LVADs) have transformed the prospects for patients with advanced heart disease refractory to optimal medical therapy. The 1-year survival rate following heart transplantation is about $90 \%$, the 5 -year rate is about $70 \%$, but only about $20 \%$ survive 20 years or longer. ${ }^{125}$ Quality of life after heart transplantation is also generally excellent and patients are frequently able to return to work, regardless of their profession. ${ }^{126}$ The leading cause of death after heart transplantation is malignancy, followed by coronary artery vasculopathy (CAV), then by graft failure. Acute rejection, which used to be one of the main causes of death, now has a low incidence due to current drugs. ${ }^{127}$ Despite its benefits, the process of transplanting a heart is drawn out and expensive, and many eligible patients simply never receive an organ due to the stagnating or decreasing number of suitable donors.

Durable left ventricular assist devices (LVADs) have become the most commonly used surgical therapy for advanced heart failure, and their use is now uncoupled from transplant candidacy. ${ }^{128}$ Historically LVADs were indicated only as a so-called bridgeto-transplantation (BTT) to ensure survival until a donor organ became available. ${ }^{129}$ Since publication of the Randomized Evaluation of Mechanical Assistance for the Treatment of Congestive Heart Failure (REMATCH) trial in 2001 that demonstrated improved survival in advanced HF patients ineligible for transplantation treated with LVAD vs. optimal medical therapy, LVADs have become increasingly approved as a more permanent 'destination therapy' (DT). ${ }^{128}$ With the advent of continuous flow devices, the 1-year survival of patients with LVADs is now in excess of $80 \% .{ }^{130}$ The vast majority of modern LVADs are continuous-flow (CF) devices. These pumps may be either centrifugal (HeartWare HVAD, Medtronic; HeartMate III,
St. Jude Medical) or axial-flow (HeartMate II, St. Jude Medical). Modern LVADs are driven electrically via a percutaneous driveline connected to a portable controller and external power source, typically batteries that are replaced every $4-18 \mathrm{~h}$, and last $>10$ years. ${ }^{131}$ Currently, $>2500$ pumps are implanted in the U.S. every year, and it is clear that a linear increase has taken place since 2006. ${ }^{132}$ Early referral for evaluation in an LVAD or transplant center is essential. Physicians should strongly consider patients who remain in NYHA III despite optimal medical therapy; other factors that may guide decision-making include inability to walk one block, hyponatremia, significant renal dysfunction, frequent HF admissions, or lack of response to CRT. ${ }^{133}$

\section{Role of Palliative Care}

Involvement of palliative care early in the course of life-limiting chronic illness has been associated with fewer invasive procedures and interventions at the end of life, decreased length of stay, and shorter admissions to intensive care units. ${ }^{134}$ The WHO recommends that palliative care should be used "early in the course of illness, in conjunction with other therapies that are intended to prolong life," as it "improves the quality of life of patients and their families facing the problem associated with life-threatening illness, through the prevention and relief of suffering. ${ }^{135} \mathrm{~A}$ cross-sectional study comparing symptomatic HF and cancer patients reported that HF patients may benefit from palliative care as much as cancer patients. ${ }^{136}$ Nevertheless, a national survey of HF specialists in 2004 found that $67 \%$ had not referred a single patient to palliative care in the 6 months prior to the survey. ${ }^{137}$ In a study of 600 patients who died from heart disease, $47 \%$ of family members said they did not receive adequate information about the disease and its progression, and $63 \%$ were unaware of the poor prognosis. ${ }^{138}$

Symptomatic management of heart failure includes loop diuretics to decrease dyspnea and improve exertional capacity and opioids to alleviate dyspnea and pain. Testosterone supplementation therapy has been shown to improve exercise capacity, muscle strength, and peak oxygen consumption 
in patients with advanced heart failure regardless of gender. ${ }^{139}$ It is important to screen patients for sleep-disordered breathing and depression, given their high prevalence among HF patients. Continuous ambulatory inotrope infusion should be considered for patients with dyspnea at rest despite maximal medical therapy. ${ }^{140}$ Medical devices such as permanent pacemakers and ICDs may no longer be indicated or desired by patients at end-of-life. About $20 \%$ of terminal heart failure patients with implantable cardioverter-defibrillators receive painful unnecessary shocks. Discontinuation of such therapies may actually improve quality of life for some patients. ${ }^{141}$

\section{Conclusions-Part 2}

Advanced heart failure leads to end-organ dysfunction, such as the development of cardiorenal syndrome, congestive hepatopathy, and heart failureinduced brain injury. Decreased blood flow can only partially explain the effect of a failing heart in other vital organs. Understanding the pathophysiological mechanisms and organ-organ interactions is key to the management of acute decompensated heart failure. The routine use of invasive hemodynamic monitoring is not recommended in acute decompensated heart failure and has not been shown to improve clinical outcomes. However, it has a utility in symptomatic patients who are refractory to standard treatment and most importantly those who are candidates for mechanical circulatory support or cardiac transplantation. There is now a role for the early initiation of mechanical circulatory support before cardiogenic shock leads to end-organ dysfunction including the use of percutaneous VADs in the setting of acute heart failure from myocardial infarction and as a bridge to recovery or definitive treatments like LVAD or heart transplantation. These advanced therapy options have significantly changed survival and quality of life for patients with heart failure who do not respond to optimal medical therapy. The clinical outcomes associated with these emerging therapeutic alternatives continue to be studied aiming to improve outcomes, and make these options available and recognizable by health care providers.
Article citation: Mantilla B, Paz P, Rahman R, Elmassry M, Shurmur S, Argueta Sosa E. Medical management of decompensated heart failure in adult patients: Part 2: Organ involvement, invasive hemodynamic monitoring, device therapy, and outcomes. The Southwest Respiratory and Critical Care Chronicles 2020;8(36):10-22

From: Department of Internal Medicine, Texas Tech University Health Sciences Center, Lubbock, Texas

Submitted: $6 / 23 / 2020$

Accepted: 8/15/2020

Reviewer: Kenneth Nugent MD

Conflicts of interest: none

This work is licensed under a Creative Commons Attribution-ShareAlike 4.0 International License.

\section{REFERENCES}

(This list includes all references from Part 1 and Part 2)

1. Yancy CW, Jessup M, Bozkurt B, et al. 2013 ACCF/AHA guideline for the management of heart failure: executive summary. Circulation 2013;128:1810-52.

2. Fonarow GC, Stough WG, Abraham WT, et al. Characteristics, treatments, and outcomes of patients with preserved systolic function hospitalized for heart failure. J Am College Card 2007;50:768-77.

3. Punnoose LR, Givertz MM, Lewis EF, et al. Heart failure with recovered ejection fraction: a distinct clinical entity. J Cardiac Failure 2011;17:527-32.

4. Fonarow GC. Factors identified as precipitating hospital admissions for heart failure and clinical outcomes: findings from OPTIMIZE-HF. Archives Internal Med 2008;168:847.

5. Opasich $\mathrm{C}$, Febo O, Riccardi $\mathrm{PG}$, et al. Concomitant factors of decompensation in chronic heart failure. Am J Card 1996;78:354-7.

6. Michalsen A, Konig G, Thimme W. Preventable causative factors leading to hospital admission with decompensated heart failure. Heart 1998;80:437-41.

7. Tsuyuki RT, McKelvie RS, Arnold JMO, et al. Acute precipitants of congestive heart failure exacerbations. Archives Internal Med 2001;161:2337.

8. Atherton JJ, Sindone A, De Pasquale CG, et al. National Heart Foundation of Australia and Cardiac Society of Australia and New Zealand: guidelines for the prevention, detection, and management of heart failure in Australia 2018. Heart Lung Circ 2018 Oct;27(10):1123-208.

9. Nohria A, Tsang SW, Fang JC, et al. Clinical assessment identifies hemodynamic profiles that predict outcomes in 
patients admitted with heart failure. J Am College Card 2003;41:1797-804.

10. Ponikowski P, Voors AA, Anker SD, et al. 2016 ESC Guidelines for the diagnosis and treatment of acute and chronic heart failure: The Task Force for the diagnosis and treatment of acute and chronic heart failure of the European Society of Cardiology (ESC). Developed with the special contribution. European J Heart Failure 2016;18:891-975.

11. Gheorghiade M, Filippatos G, De Luca L, et al. Congestion in acute heart failure syndromes: an essential target of evaluation and treatment. Am J Med 2006;119: S3-S10.

12. Gheorghiade M, Follath F, Ponikowski P, et al. Assessing and grading congestion in acute heart failure: a scientific statement from the acute heart failure committee of the heart failure association of the European Society of Cardiology and endorsed by the European Society of Intensive Care Medicine. European J Heart Failure 2010;12:423-33.

13. Cotter G, Metra M, Milo-Cotter O, et al. Fluid overload in acute heart failure-re-distribution and other mechanisms beyond fluid accumulation. European J Heart Failure 2008;10:165-9.

14. McMurray JJ, Adamopoulos S, Anker SD, et al. ESC Guidelines for the diagnosis and treatment of acute and chronic heart failure 2012: The Task Force for the Diagnosis and Treatment of Acute and Chronic Heart Failure 2012 of the European Society of Cardiology. Developed in collaboration with the Heart Failure Association (HFA) of the ESC. Eur Heart J 2012;33:1787-847.

15. Yancy CW, Jessup M, Bozkurt B, et al. 2013 ACCF/AHA guideline for the management of heart failure: a report of the American College of Cardiology Foundation/American Heart Association Task Force on practice guidelines. Circulation 2013;128:e240-327.

16. Aliti GB, Rabelo ER, Clausell N, et al. Aggressive fluid and sodium restriction in acute decompensated heart failure: a randomized clinical trial. JAMA Internal Med 2013;173: 1058-64.

17. Travers B, O'Loughlin C, Murphy NF, et al. Fluid restriction in the management of decompensated heart failure: no impact on time to clinical stability. J Card Fail 2007;13: 128-32.

18. Yancy CW, Jessup M, Bozkurt B, et al. 2013 ACCF/AHA guideline for the management of heart failure: a report of the American College of Cardiology Foundation/American Heart Association Task Force on Practice Guidelines. J Am College Card 2013;62:e147-239.

19. Lindenfeld J, Albert NM, Boehmer JP, et al. HFSA 2010 comprehensive heart failure practice guideline. J Card Fail 2010;16: e1-194.

20. Stampfer M, Epstein SE, Beiser GD, et al. Hemodynamic effects of diuresis at rest and during intense upright exercise in patients with impaired cardiac function. Circulation 1968;37:900-11.

21. Matsue Y, Damman K, Voors AA, et al. Time-to-furosemide treatment and mortality in patients hospitalized with acute heart failure. J Am Coll Cardiol 2017;69:3042-51.

22. Hunt SA, Abraham WT, Chin MH, et al. 2009 focused update incorporated into the ACC/AHA 2005 guidelines for the diagnosis and management of heart failure in adults: a report of the American College of Cardiology Foundation/ American Heart Association task force on practice guidelines: developed in collaboration with the International Society for Heart and Lung Transplantation. Circulation 2009; 119:e391-479.

23. Felker GM, Lee KL, Bull DA, et al. Diuretic strategies in patients with acute decompensated heart failure. N Engl J Med 2011;364:797-805.

24. Felker GM, O’Connor CM, Braunwald E. Loop diuretics in acute decompensated heart failure: necessary? Evil? A necessary evil? Circulation Heart failure 2009;2:56-62.

25. Pappas L, Filippatos G. Pulmonary congestion in acute heart failure: from hemodynamics to lung injury and barrier dysfunction. Revista Española de Cardiología (English Edition) 2011;64:735-8.

26. Valente MAE, Voors AA, Damman $K$, et al. Diuretic response in acute heart failure: clinical characteristics and prognostic significance. European Heart J 2014;35:1284-93.

27. Voors AA, Davison BA, Teerlink JR, et al. Diuretic response in patients with acute decompensated heart failure: characteristics and clinical outcome - an analysis from RELAX-AHF. European J Heart Failure 2014;16:1230-40.

28. Bowman BN, Nawarskas JJ, Anderson JR. Treating diuretic resistance: an overview. Cardiology Review 2016;24: 256-60.

29. Shah N, Madanieh R, Alkan M, et al. A perspective on diuretic resistance in chronic congestive heart failure 2017.

30. Jentzer JC, DeWald TA, Hernandez AF. Combination of loop diuretics with thiazide-type diuretics in heart failure. J Am College Card 2010;56:1527-34.

31. Eng M, Bansal S. Use of natriuretic-doses of spironolactone for treatment of loop diuretic resistant acute decompensated heart failure. International J Card 2004;170:E68-E69.

32. Kitsios GD, Mascari P, Ettunsi R, et al. Co-administration of furosemide with albumin for overcoming diuretic resistance in patients with hypoalbuminemia: a meta-analysis. J Critical Care 2014;29:253-9.

33. Liszkowski M, Nohria A. Rubbing salt into wounds: hypertonic saline to assist with volume removal in heart failure. Current Heart Failure Reports 2010;7:134-9.

34. Wakai A, McCabe A, Kidney R, et al. Nitrates for acute heart failure syndromes. The Cochrane database of systematic reviews 2013:CD005151-CD. 
35. CotterG, MetzkorE, KaluskiE, etal.Randomised trial ofhighdose isosorbide dinitrate plus low-dose furosemide versus high-dose furosemide plus low-dose isosorbide dinitrate in severe pulmonary oedema. Lancet (London, England) 1998; 351:389-93.

36. Hsu HO, Hickey RF, Forbes AR. Morphine decreases peripheral vascular resistance and increases capacitance in man. Anesthesiology 1979;50:98-102.

37. Pur-Shahriari AA, Mills RA, Hoppin FG, Jr., et al. Comparison of chronic and acute effects of morphine sulfate on cardiovascular function. Am J Cardiol 1967;20:654-9.

38. Acute heart failure: diagnosing and managing acute heart failure in adults. London: National Institute for Health and Care Excellence (UK) National Clinical Guideline Centre, 2014;2014.

39. Peacock WF, Hollander JE, Diercks DB, et al. Morphine and outcomes in acute decompensated heart failure: an ADHERE analysis. Emerg Med J 2008;25:205-9.

40. Sharon A, Shpirer I, Kaluski E, et al. High-dose intravenous isosorbide-dinitrate is safer and better than Bi-PAP ventilation combined with conventional treatment for severe pulmonary edema. J Am Coll Cardiol 2000;36:832-7.

41. O'Connor CM, Starling RC, Hernandez AF, et al. Effect of nesiritide in patients with acute decompensated heart failure. N Engl J Med 2011;365:32-43.

42. Kozhuharov N, Goudev A, Flores D, et al. Effect of a strategy of comprehensive vasodilation vs usual care on mortality and heart failure rehospitalization among patients with acute heart failure: the GALACTIC randomized clinical trial. JAMA 2019;322:2292-302.

43. Wang K, Samai K. Role of high-dose intravenous nitrates in hypertensive acute heart failure. Am J Emerg Med 2020; 38:132-7.

44. Konstam MA, Gheorghiade M, Burnett JC, et al. Effects of oral tolvaptan in patients hospitalized for worsening heart failure: the EVEREST outcome trial. JAMA 2007;297: 1319-31.

45. Cuffe MS, Califf RM, Adams KF, Jr., et al. Short-term intravenous milrinone for acute exacerbation of chronic heart failure: a randomized controlled trial. JAMA 2002;287: 1541-7.

46. Burger AJ, Elkayam U, Neibaur MT, et al. Comparison of the occurrence of ventricular arrhythmias in patients with acutely decompensated congestive heart failure receiving dobutamine versus nesiritide therapy. Am J Cardiol 2001;88: 35-9.

47. Abraham WT, Adams KF, Fonarow GC, et al. In-hospital mortality in patients with acute decompensated heart failure requiring intravenous vasoactive medications: an analysis from the Acute Decompensated Heart Failure National Registry (ADHERE). J Am Coll Cardiol 2005;46:57-64.
48. Bourke SC, Piraino T, Pisani L, et al. Beyond the guidelines for non-invasive ventilation in acute respiratory failure: implications for practice. Lancet Respiratory Med 2018;6: 935-47.

49. Hildebrandt J, Beck K, Scherba S, et al. Pulmonary interstitial and capillary pressures estimated from intra-alveolar fluid pressures. J Appl Physiol Respir Environ Exerc Physiol 1979 Sep;47(3):643-41979:643-4.

50. Inoue $H$, Inoue $C$, Hildebrandt J. Vascular and airway pressures, and interstitial edema, affect peribronchial fluid pressure. J Applied Physiology 1980;48:177-85.

51. Malo J, Ali J, Wood LD. How does positive end-expiratory pressure reduce intrapulmonary shunt in canine pulmonary edema? J Applied Physiology 1984;57:1002-10.

52. Bersten AD, Holt AW, Vedig AE, et al. Treatment of severe cardiogenic pulmonary edema with continuous positive airway pressure delivered by face mask. N Engl J Med 1991; 325:1825-30.

53. Staub NC, Nagano H, Pearce ML. Pulmonary edema in dogs, especially the sequence of fluid accumulation in lungs. J Applied Physiology 1967;22:227-40.

54. Dreyfuss D, Basset G, Soler P, et al. Intermittent positivepressure hyperventilation with high inflation pressures produces pulmonary microvascular injury in rats. Am Rev Resp Dis 1985;132:880-4.

55. $\mathrm{Fu} \mathrm{Z}$, Costello ML, Tsukimoto $\mathrm{K}$, et al. High lung volume increases stress failure in pulmonary capillaries. J Applied Physiology (Bethesda, Md: 1985) 1992;73:123-33.

56. Faridy EE, Permutt S, Riley RL. Effect of ventilation on surface forces in excised dogs' lungs. J Applied Physiology 1966;21:1453-62.

57. McClenahan JB, Urtnowski A. Effect of ventilation on surfactant, and its turnover rate. J Applied Physiology 1967;23: 215-20.

58. Wyszogrodski I, Kyei-Aboagye K, Taeusch HW, Jr., et al. Surfactant inactivation by hyperventilation: conservation by end-expiratory pressure. J Applied Physiology 1975;38: 461-6.

59. Albert RK. The role of ventilation-induced surfactant dysfunction and atelectasis in causing acute respiratory distress syndrome. Am J Resp Crit Care Med 2012;185:702-8.

60. Guyton AC, Lindsey AW, Abernathy B, et al. Venous return at various right atrial pressures and the normal venous return curve. Am J Physiology 1957;189:609-15.

61. Pinsky MR. Determinants of pulmonary arterial flow variation during respiration. J Applied Physiology 1984;56:1237-45.

62. Pinsky MR. Instantaneous venous return curves in an intact canine preparation. J Applied Physiology 1984;56:765-71.

63. Luecke T, Pelosi P. Clinical review: Positive end-expiratory pressure and cardiac output. Critical Care (London, England) 2005;9:607-21. 
64. Klinger JR. Hemodynamics and positive end-expiratory pressure in critically ill patients. Critical Care Clinics 1996; 12:841-64.

65. Crane SD, Elliott MW, Gilligan P, et al. Randomised controlled comparison of continuous positive airways pressure, bilevel non-invasive ventilation, and standard treatment in emergency department patients with acute cardiogenic pulmonary oedema. Emergency Med J 2004;21:155-61.

66. Kelly CA, Newby DE, McDonagh TA, et al. Randomised controlled trial of continuous positive airway pressure and standard oxygen therapy in acute pulmonary oedema; effects on plasma brain natriuretic peptide concentrations. European Heart J 2002;23:1379-86.

67. L'Her E, Duquesne F, Girou E, et al. Noninvasive continuous positive airway pressure in elderly cardiogenic pulmonary edema patients. Intensive Care Med 2004;30:882-8.

68. Lin M, Yang YF, Chiang HT, et al. Reappraisal of continuous positive airway pressure therapy in acute cardiogenic pulmonary edema. Short-term results and long-term follow-up. Chest 1995;107:1379-86.

69. Masip J, Betbese AJ, Paez J, et al. Non-invasive pressure support ventilation versus conventional oxygen therapy in acute cardiogenic pulmonary oedema: a randomised trial. Lancet (London, England) 2000;356:2126-32.

70. Nava S, Carbone G, DiBattista N, et al. Noninvasive ventilation in cardiogenic pulmonary edema: a multicenter randomized trial. Am J Resp Critical Care Med 2003;168:1432-7.

71. Park M, Sangean MC, Volpe MdS, et al. Randomized, prospective trial of oxygen, continuous positive airway pressure, and bilevel positive airway pressure by face mask in acute cardiogenic pulmonary edema. Critical Care Med 2004;32: 2407-15.

72. Takeda S, Nejima J, Takano T, et al. Effect of nasal continuous positive airway pressure on pulmonary edema complicating acute myocardial infarction. Japanese Circulation J 1998;62:553-8.

73. Gray A, Goodacre S, Newby DE, et al. Noninvasive ventilation in acute cardiogenic pulmonary edema. N Engl J Med 2008;359:142-51.

74. Masip J, Mebazaa A, Filippatos GS. Noninvasive ventilation in acute cardiogenic pulmonary edema. N Engl J Med 2008;359:2068-9; author reply 9.

75. Masip J, Roque M, Sanchez B, et al. Noninvasive ventilation in acute cardiogenic pulmonary edema: systematic review and meta-analysis. JAMA 2005;294:3124-30.

76. Vital FMR, Saconato H, Ladeira MT, et al. Non-invasive positive pressure ventilation (CPAP or bilevel NPPV) for cardiogenic pulmonary edema. The Cochrane database of systematic reviews 2008:CD005351-CD.

77. Winck JC, Azevedo LF, Costa-Pereira A, et al. Efficacy and safety of non-invasive ventilation in the treatment of acute cardiogenic pulmonary edema-a systematic review andmetaanalysis. Critical Care (London, England) 2006;10: R69-R.

78. National Heart L, Institute B. NHLBI Working Group: Cardio-renal connections in heart failure and cardiovascular disease, 2004. 2014.

79. Ronco C, Haapio M, House AA, et al. Cardiorenal syndrome. J Am Coll Cardiol 2008;52:1527-39.

80. Hanberg JS, Sury K, Wilson FP, et al. Reduced cardiac index is not the dominant driver of renal dysfunction in heart failure. J Am Coll Cardiol 2016;67:2199-208.

81. Correale M, Tarantino N, Petrucci R, et al. Liver disease and heart failure: Back and forth. Eur J Intern Med 2018; 48:25-34.

82. Giallourakis CC, Rosenberg PM, Friedman LS. The liver in heart failure. Clin Liver Dis 2002;6:947-67, viii-ix.

83. Alvarez AM, Mukherjee D. Liver abnormalities in cardiac diseases and heart failure. Int J Angiol 2011;20:135-42.

84. Poelzl G, Ess M, Mussner-Seeber C, et al. Liver dysfunction in chronic heart failure: prevalence, characteristics and prognostic significance. Eur J Clin Invest 2012;42: 153-63.

85. Higashiyama H, Yamaguchi M, Kumada K, et al. Functional deterioration of the liver by elevated inferior vena cava pressure: a proposed upper safety limit of pressure for maintaining liver viability in dogs. Intensive Care Med 1994;20: 124-9.

86. Fouad YM, Yehia R. Hepato-cardiac disorders. World J Hepatol 2014;6:41-54.

87. Lau GT, Tan HC, Kritharides L. Type of liver dysfunction in heart failure and its relation to the severity of tricuspid regurgitation. Am J Cardiol 2002;90:1405-9.

88. Styczynski G, Milewska A, Marczewska M, et al. Echocardiographic correlates of abnormal liver tests in patients with exacerbation of chronic heart failure. J Am Soc Echocardiogr 2016;29:132-9.

89. Allen LA, Felker GM, Pocock S, et al. Liver function abnormalities and outcome in patients with chronic heart failure: data from the Candesartan in Heart Failure: Assessment of Reduction in Mortality and Morbidity (CHARM) program. Eur J Heart Fail 2009;11:170-7.

90. Shah S, Sass D. Cardiac hepatopathy: a review of liver dysfunction in heart failure. Liver Res Open J 2015;1:1-10.

91. Rajagopalan B, Raine AE, Cooper R, et al. Changes in cerebral blood flow in patients with severe congestive cardiac failure before and after captopril treatment. Am J Med 1984;76:86-90.

92. Georgiadis D, Sievert M, Cencetti S, et al. Cerebrovascular reactivity is impaired in patients with cardiac failure. Eur Heart J 2000;21:407-13.

93. Derdeyn CP, Videen TO, Yundt KD, et al. Variability of cerebral blood volume and oxygen extraction: stages of cerebral 
haemodynamic impairment revisited. Brain 2002;125: 595-607.

94. Lorenzi-Filho G, Azevedo ER, Parker JD, et al. Relationship of carbon dioxide tension in arterial blood to pulmonary wedge pressure in heart failure. Eur Respir J 2002;19: 37-40.

95. Almeida OP, Garrido GJ, Beer C, et al. Cognitive and brain changes associated with ischaemic heart disease and heart failure. Eur Heart J 2012;33:1769-76.

96. Vogels RL, Scheltens P, Schroeder-Tanka JM, et al. Cognitive impairment in heart failure: a systematic review of the literature. Eur J Heart Fail 2007;9:440-9.

97. Roman GC. Brain hypoperfusion: a critical factor in vascular dementia. Neurol Res 2004;26:454-8.

98. Bhat G, Yost G, Mahoney E. Cognitive function and left ventricular assist device implantation. J Heart Lung Transplant 2015;34:1398-405.

99. Roman DD, Kubo SH, Ormaza S, et al. Memory improvement following cardiac transplantation. J Clin Exp Neuropsychol 1997;19:692-7.

100. Zuccala G, Onder G, Marzetti E, et al. Use of angiotensin-converting enzyme inhibitors and variations in cognitive performance among patients with heart failure. Eur Heart J 2005;26:226-33.

101. Paulson OB, Waldemar G, Andersen AR, et al. Role of angiotensin in autoregulation of cerebral blood flow. Circulation 1988;77:I55-8.

102. Davey R, Raina A. Hemodynamic monitoring in heart failure and pulmonary hypertension: From analog tracings to the digital age. World J Transplantation 2016;6:542.

103. Binanay C, Califf RM, Hasselblad V, et al. Evaluation study of congestive heart failure and pulmonary artery catheterization effectiveness: the ESCAPE trial. JAMA 2005;294: 1625-33.

104. Shah MR, Hasselblad V, Stevenson LW, et al. Impact of the pulmonary artery catheter in critically ill patients. JAMA 2005;294:1664

105. Wolfson AM, Fong M, Grazette L, et al. Chronic heart failure management and remote haemodynamic monitoring. Heart 2018;104:1910-9.

106. Sodhi N, Lasala JM. Mechanical circulatory support in acute decompensated heart failure and shock. Interventional Cardiology Clinics 2017;6:387-405.

107. Lawson WE, Koo M. Percutaneous ventricular assist devices and ECMO in the management of acute decompensated heart failure. Clinical Medicine Insights: Cardiology 2015; 9s1:CMC.S19701.

108. Thiele H, Zeymer U, Neumann F-J, et al. Intra-aortic balloon support for myocardial infarction with cardiogenic shock. N Engl J Med 2012;367:1287-96.
109. Stretch R, Sauer CM, Yuh DD, et al. National trends in the utilization of short-term mechanical circulatory support. J Am College Cardiology 2014;64:1407-15.

110. O’Neill WW, Kleiman NS, Moses J, et al. A prospective, randomized clinical trial of hemodynamic support with Impella 2.5 versus intra-aortic balloon pump in patients undergoing high-risk percutaneous coronary intervention. Circulation 2012;126:1717-27.

111. Vetrovec GW, Anderson $M$, Schreiber T, et al. The cVAD registry for percutaneous temporary hemodynamic support: A prospective registry of Impella mechanical circulatory support use in high-risk PCI, cardiogenic shock, and decompensated heart failure. Am Heart J 2018;199:115-21.

112. O'Neill WW, Schreiber T, Wohns DHW, et al. The current use of Impella 2.5 in acute myocardial infarction complicated by cardiogenic shock: results from the USpella registry. J Interventional Card 2013;27:1-11.

113. Rihal CS, Naidu SS, Givertz MM, et al. 2015 SCAI/ACC/ HFSA/STS clinical expert consensus statement on the use of percutaneous mechanical circulatory support devices in cardiovascular care. J Am College Card 2015;65: e7-e26.

114. Abrams D, Combes A, Brodie D. Extracorporeal membrane oxygenation in cardiopulmonary disease in adults. J Am College Card 2014;63:2769-78.

115. Meani P, Pappalardo F. The step forward for VA ECMO: left ventricular unloading! J Thoracic Disease 2017;9:4149-51.

116. Dolmatova EV, Moazzami K, Cocke TP, et al. Extracorporeal membrane oxygenation in massive pulmonary embolism. Heart Lung 2017;46:106-9.

117. Allen LA, Stevenson LW, Grady KL, et al. Decision making in advanced heart failure: a scientific statement from the American Heart Association. Circulation 2012;125: 1928-52.

118. Metra M, Eichhorn E, Abraham WT, et al. Effects of lowdose oral enoximone administration on mortality, morbidity, and exercise capacity in patients with advanced heart failure: the randomized, double-blind, placebo-controlled, parallel group ESSENTIAL trials. European Heart J 2009;30: 3015-26.

119. Nadruz Jr W, West E, Santos M, et al. Heart failure and midrange ejection fraction: implications of recovered ejection fraction for exercise tolerance and outcomes. Circulation: Heart Failure 2016;9: e002826.

120. Givertz MM, Mann DL. Epidemiology and natural history of recovery of left ventricular function in recent onset dilated cardiomyopathies. Curr Heart Fail Rep 2013;10:321-30.

121. Rigolli M, Cicoira M, Bergamini C, et al. Progression of left ventricular dysfunction and remodelling under optimal medical therapy in CHF patients: role of individual genetic background. Card Research Practice 2011;2011. 
122. Jansweijer JA, Nieuwhof $K$, Russo F, et al. Truncating titin mutations are associated with a mild and treatable form of dilated cardiomyopathy. European J Heart Failure 2017; 19:512-21.

123. Proclemer A, Muser D, Facchin D. What we can learn from "super-responders." Heart Failure Clinics 2017;13: 225-32.

124. Gulati G, Udelson JE. Heart failure with improved ejection fraction: is it possible to escape one's past? JACC: Heart Failure 2018;6:725-33.

125. Mancini D, Lietz K. Selection of cardiac transplantation candidates in 2010. Circulation 2010;122:173-83.

126. Starling RC. Improved quantity and quality of life: a winning combination to treat advanced heart failure. J Am Coll Cardiol 2010;55:1835-6.

127. Lietz K, Miller LW. Improved survival of patients with end-stage heart failure listed for heart transplantation: analysis of organ procurement and transplantation network/U.S. United Network of Organ Sharing data, 1990 to 2005. J Am Coll Cardiol 2007;50:1282-90.

128. Rose EA, Gelijns AC, Moskowitz AJ, et al. Long-term use of a left ventricular assist device for end-stage heart failure. N Engl J Med 2001;345:1435-43.

129. Miller LW, Pagani FD, Russell SD, et al. Use of a continuousflow device in patients awaiting heart transplantation. N Engl J Med 2007;357:885-96.

130. Rogers JG, Butler J, Lansman SL, et al. Chronic mechanical circulatory support for inotrope-dependent heart failure patients who are not transplant candidates: results of the INTrEPID Trial. J Am College Card 2007;50:741-7.

131. Gustafsson F, Rogers JG. Left ventricular assist device therapy in advanced heart failure: patient selection and outcomes. European J Heart Failure 2017;19:595-602.
132. Holman WL, Pae WE, Teutenberg JJ, et al. INTERMACS: interval analysis of registry data. J Am College Surgeons 2009;208:755-61.

133. Russell SD, Miller LW, Pagani FD. Advanced heart failure: a call to action. Congestive Heart Failure 2008;14:316-21.

134. Brenda EF, Lynn ED, Richard WC. Impact of a comprehensive supportive care team on management of hopelessly iii patients with multiple organ failure. Chest 1989;96:353-6.

135. World Health Organization definition of palliative care. World Health Organization Website https:/www.who.int/ cancer/palliative/definition/en/ Accessed 5/25/2020

136. Bekelman DB, Rumsfeld JS, Havranek EP, et al. Symptom burden, depression, and spiritual well-being: a comparison of heart failure and advanced cancer patients. J General Internal Med 2009;24:592-8.

137. Riegel B, Moser DK, Powell M, et al. Nonpharmacologic care by heart failure experts. J Cardiac Failure 2006;12:149. e1-.e11.

138. McCarthy M, Addington Hall J, Ley M. Communication and choice in dying from heart disease. J Royal Society Med 1997;90:128-31.

139. Caminiti G, Volterrani M, Iellamo F, et al. Effect of longacting testosterone treatment on functional exercise capacity, skeletal muscle performance, insulin resistance, and baroreflex sensitivity in elderly patients with chronic heart failure: a double-blind, placebo-controlled, randomized study. J Am College Card 2009;54:919-27.

140. Hershberger RE, Nauman D, Walker TL, et al. Care processes and clinical outcomes of continuous outpatient support with inotropes (COSI) in patients with refractory endstage heart failure. J Card Fail 2003;9:180-7.

141. Nambisan V, Chao D. Dying and defibrillation: a shocking experience. Palliat Med 2004;18:482-3. 